\title{
Microstructural evolution of nanocrystalline magnetite synthesized by electrocoagulation
}

\author{
Ying-Chieh Weng \\ Department of Chemical Engineering, National Taiwan University, Taipei 106, \\ Taiwan, Republic of China \\ I.A. Rusakova and Andrei Baikalov \\ Texas Center for Superconductivity and Advanced Materials, University of Houston, \\ Houston, Texas 77204-5932 \\ J.W. Chen \\ Department of Physics, National Taiwan University, Taipei 106, Taiwan, Republic of China \\ $\mathrm{Nae}-\mathrm{Lih} \mathrm{Wu}^{\mathrm{a}}$ \\ Department of Chemical Engineering, National Taiwan University, Taipei 106, \\ Taiwan, Republic of China
}

(Received 28 April 2004; accepted 21 September 2004)

\begin{abstract}
Nanocrystalline magnetite powders were synthesized by an electrocoagulation technique, in which an electric current was passed across two plate electrodes of carbon steel immersed in $\mathrm{NaCl}_{(\mathrm{aq})}$ electrolyte, and the microstructure of the oxide powder was found to evolve in roughly three stages. The first stage involves formation and growth of severely defective colloidal crystallites. This is followed by agglomeration among the oxide crystallites to form mesoporous agglomerates containing predominantly inter-crystallite pores, and the average crystallite size was found to reach a plateau. Finally, coarsening of the crystallites within the agglomerates leads to another rapid increase in crystallite size and reduction in pore opening. The synthesized powders typically showed a saturation magnetization of $\sim 75 \mathrm{emu} / \mathrm{g}$ and a coercivity $H_{\mathrm{c}}$ of $\sim 118 \mathrm{Oe}$. A mechanism involving competition between nucleation and growth of free colloids and coarsening of the skeletal framework was proposed to explain the temporary level-off in crystallite size during the synthesis.
\end{abstract}

\section{INTRODUCTION}

Magnetite $\left(\mathrm{Fe}_{3} \mathrm{O}_{4}\right)$ has long been a material of both industrial and scientific interests. It has been used, for instance, as a black pigment, ${ }^{1}$ a recording media, ${ }^{2}$ a magnetic component in magnetic fluids, ${ }^{3}$ and a magnetic carrier for bioseparation and drug delivery. ${ }^{4,5}$ Photocatalystcoated magnetite has also been suggested for decomposition of organics in wastewater treatment. ${ }^{6}$ Different applications may prefer different microstructural properties, in addition to the magnetic ones. For instance, the magnetic fluid and recording applications favor nonporous nanocrystalline particles, while catalysis and biological and medical applications prefer large surface area and mesoporosity. As a result, many synthesis methods, such as precipitation, ${ }^{7}$ microemulsion, ${ }^{8}$ hydrothermal, ${ }^{9,10}$ solventothermal, ${ }^{11,12}$ and microwave hydrothermal, ${ }^{13,14}$

\footnotetext{
a) Address all correspondence to this author.

e-mail: nlw001@ntu.edu.tw

DOI: $10.1557 / J M R .2005 .0003$
}

have been developed to give magnetite powders of particular microstructures to meet the application requirements.

Tsouris et al. ${ }^{15-17}$ recently reported an electrocoagulation (EC) method for producing nanocrystalline magnetite powder, where $\mathrm{Fe}$ ions are produced at the anode through electrochemical oxidation and then react with water to form the oxide. The oxide particles are then coagulated due to adsorption of ions on particle surface to neutralize the charge of the particles. Compared with other solution synthesis methods, ${ }^{7-14}$ the EC method has the advantages of low-cost, continuous-process flexibility, and in particular, not producing wastewater that contains high concentrations of anions, such as $\mathrm{Cl}^{-}$and $\mathrm{NO}_{3}{ }^{-}$, associated with the starting Fe-containing salts. We also recently demonstrated that the EC magnetite powders show promise in supercapacitor application due to its high surface area and superficial electrochemical activity. ${ }^{18}$

Although there have been reports on the electrochemical behaviors of the process, ${ }^{16,17}$ the microstructures of 
the resulted magnetite powder have not been well established. In this work, the microstructural properties, including crystallite size, surface area, and porosity, of the EC magnetite powder have been characterized as a function of synthesis time, current and temperature. Magnetite in the form of colloidal crystallites and mesoporous skeletal agglomerates of varied compactness have been synthesized, and a microstructural evolution mechanism that accounts for the microstructural variations is proposed.

\section{EXPERIMENTAL}

The eletrocoagulation process was carried out by immersing two plates of carbon steel in a $0.04 \mathrm{M} \mathrm{NaCl}_{(\mathrm{aq})}$ solution and applying a constant current to the electrodes. The carbon steel plates have an $8 \times 8 \mathrm{~cm}$ dimension, and the process was conducted in a 2-liter beaker. During the process, the electrolyte solution was vigorously agitated by constantly bubbling with synthetic air $\left(\mathrm{N}_{2}: \mathrm{O}_{2}=79\right.$ : 21). A constant current of either 4.0 or 8.0 A (corresponding to a current density of 62.5 and $125 \mathrm{~mA} / \mathrm{cm}^{2}$ ) was used, while two synthesis temperatures, 30 and $70{ }^{\circ} \mathrm{C}$, have been used. Magnetite powders were collected by precipitation assisted with a magnet, washed three times with de-ionized water, and finally dried under vacuum at ambient temperature.

Average crystallite size was determined by x-ray diffraction (XRD; Mac-Science/MXP, Tokyo, Japan) based on the Scherrer equation ${ }^{19}$

$$
d=0.9 \lambda /\left(B^{2}-b^{2}\right)^{1 / 2} \cos \theta,
$$

where $d$ is the average crystallite size $(\mathrm{nm}) ; \lambda$, the wavelength of $\mathrm{x}$-ray $(\lambda=0.15418 \mathrm{~nm}) ; \theta$, the Bragg angle of the (311) reflection of magnetite; $B$, the full width of the peak at half-maximum intensity; and $b$, the line broadening width of the equipment. Transmission electron microscopy (TEM) analysis was carried out on a Hitachi H7100 electron microscope (Tokyo, Japan), while the high-resolution (HR) TEM micrographs were taken on a JEOL 2000 FX (Tokyo, Japan), which operates at $200 \mathrm{kV}$ and is equipped with energy dispersive analysis of $\mathrm{X}$-ray (EDX) analyzer. Nitrogen adsorption (ASAP2010, Micromeritics, Norcross, GA) was conducted to determine the Brunauer-Emmett-Teller (BET) surface area and the pore characteristics. Magnetization analysis was carried out on a SQUID (Quantum Design MPMS-5S, San Diego, CA).

\section{RESULTS AND DISCUSSION}

As the electrocoagulation process proceeded, the solution, which was initially transparent, was found to gradually turn first yellowish, then brownish, and finally black. The last two colors actually originated from the suspended particles, and powders exhibiting the same colors could be obtained when the solution was allowed to settle. Concurrently, the solution $\mathrm{pH}$ increased from being nearly neutral, then to 7-8 (brownish) and to the saturation at approximately 11 (black). The time needed for the color and $\mathrm{pH}$ to reach their final states was found to decrease with increasing current, being approximately 20 and $10 \mathrm{~min}$ for the 4.0 and 8.0 A-runs, respectively.

XRD of both the brownish and black powders showed reflections typical of magnetite [Fig. 1(a)], suggesting that they possess the same fundamental structure. However, the brownish one exhibits larger $d$-spacings [Fig. 1(b)]. Based on a face-centric-cubic (fcc) structure, the least-square fitting of the $d$-spacing data acquired from the $2 \theta$ range between $20^{\circ}$ and $70^{\circ}$ gives the brownish powder a lattice parameter $a_{\mathrm{o}}=0.846 \mathrm{~nm}$, in contrast with $a_{\mathrm{o}}=0.839 \mathrm{~nm}$ for the black powder. The brownish phase is to be distinguished from $\gamma-\mathrm{Fe}_{2} \mathrm{O}_{3}$, which has almost the same sets of XRD reflections as magnetite but with smaller $d$-spacings. The exact composition of the
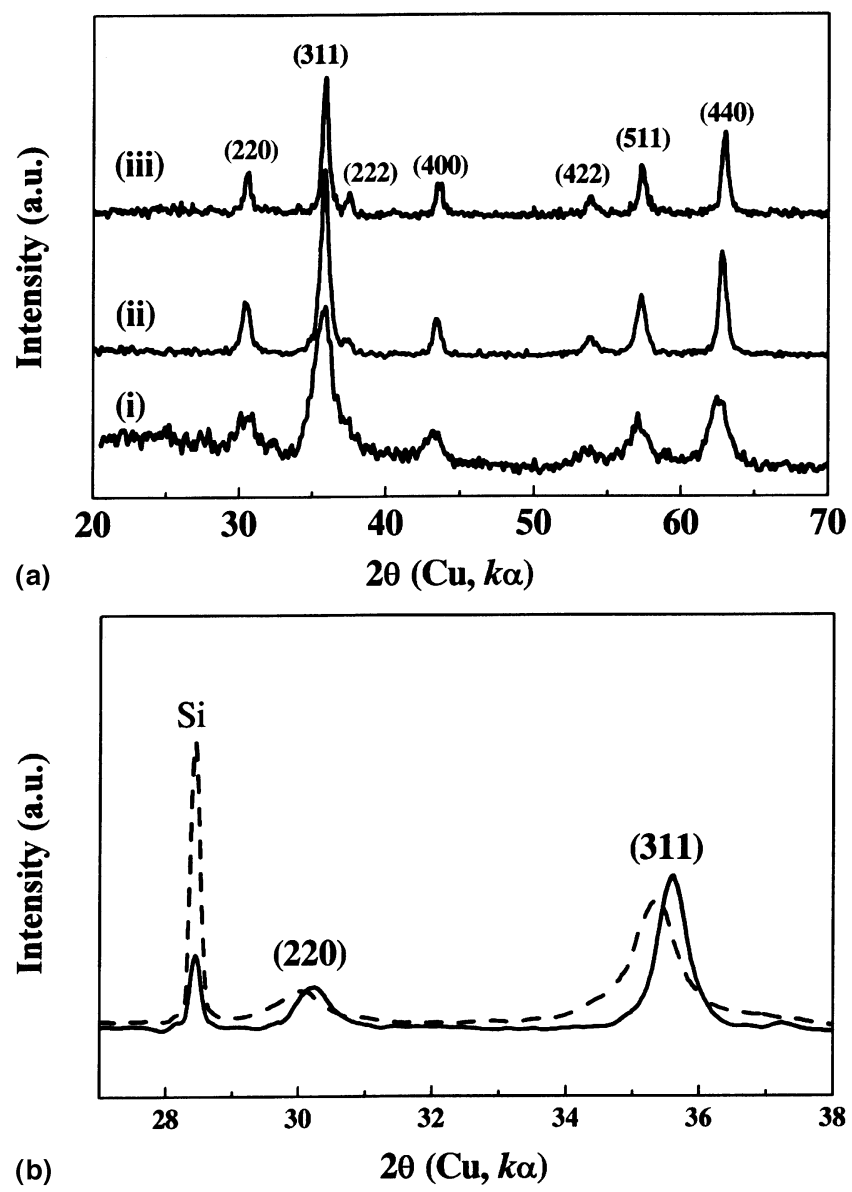

FIG. 1. (a) XRD patterns for the powder synthesized under different conditions: (i) $4.0 \mathrm{~A}, 10 \mathrm{~min}$; (ii) $4.0 \mathrm{~A}, 50 \mathrm{~min}$; and (iii) $8.0 \mathrm{~A}$; $50 \mathrm{~min}$. (b) Comparison between the black (solid line) and brownish (dashed line) powders, with $\mathrm{Si}$ internal standard, showing that the brownish powder has larger $d$-spacings than the black one. 
brownish phase is not for certain at this point. In a previous report by Dhage et al. ${ }^{14}$ on the $\mathrm{pH}$ effect on crystallization of iron oxides, it has been shown that the composition of the magnetite crystallites depends on the $\mathrm{pH}$. The $\mathrm{pH}$ conditions under which the brownish powder is formed in the present study lead to the formation of non-stoichiometric magnetite, which has $\mathrm{Fe}^{+3}$ vacancies at the octahedral sites in the spinel structure. The presence of the cation vacancies is consistent with the expansion in the lattice parameter $a_{\mathrm{o}}$ observed in this study.

Figure 2 summarizes the crystallite size data calculated based on the XRD results. It was found that, under the same current and temperature, the brownish powder in general has a smaller crystallite size and that, when the powder color turned from brownish to black with increasing synthesis time, the crystallite size first reached a plateau for certain period of time before finally increasing again. The plateau crystallite size (PCS) is larger for lower current, being approximately 10 and $6 \mathrm{~nm}$ for the 4.0 and $8.0 \mathrm{~A}$ at $30^{\circ} \mathrm{C}$, respectively. Increasing synthesis temperature tends to increase the PCS as well. These crystallite sizes are between those previously reported for magnetite synthesized by a coprecipitation method $(\sim 8 \mathrm{~nm})^{8}$ and by a microwave hydrothermal method $(\sim 34 \mathrm{~nm}){ }^{13}$

Nitrogen adsorption revealed that the powders consisted of predominantly meso- $(2-50 \mathrm{~nm})$ and macro- $(<50 \mathrm{~nm})$

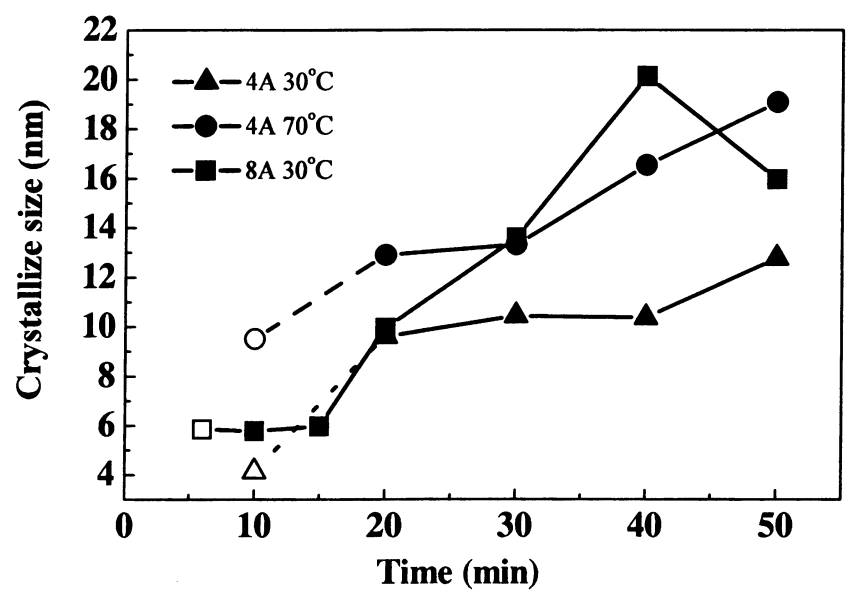

FIG. 2. Average crystallite size versus synthesis time for different conditions. $\square \square$ : black and brownish powders produced with $8.0 \mathrm{~A}$, $30{ }^{\circ} \mathrm{C} ; \boldsymbol{\Delta} \triangle$ : with $4.0 \mathrm{~A}, 30{ }^{\circ} \mathrm{C} ; \bigcirc$ : with $4.0 \mathrm{~A}, 70{ }^{\circ} \mathrm{C}$.

TABLE I. Nitrogen adsorption data of selected powders.

\begin{tabular}{lcccc}
\hline \hline & $\begin{array}{c}\text { BET } \\
\text { surface } \\
\text { area } \\
\left(\mathrm{m}^{2} / \mathrm{g}\right)\end{array}$ & $\begin{array}{c}\text { Micropore } \\
\text { surface } \\
\text { area } \\
\left(\mathrm{m}^{2} / \mathrm{g}\right)\end{array}$ & $\begin{array}{c}\text { Total pore } \\
\text { volume } \\
(\text { diameter } \\
<70 \mathrm{~nm}) \\
\left(10^{-3} \mathrm{~cm}^{3} / \mathrm{g}\right)\end{array}$ & $\begin{array}{c}\text { Micropore } \\
\text { volume } \\
\left(10^{-3} \mathrm{~cm}^{3} / \mathrm{g}\right)\end{array}$ \\
Synthesis conditions & 36.9 & 4.09 & 148 & 1.57 \\
$4.0 \mathrm{~A}, 30^{\circ} \mathrm{C}, 30 \mathrm{~min}$ & 3.25 & 122 & 1.18 \\
$8.0 \mathrm{~A}, 30^{\circ} \mathrm{C}, 20 \mathrm{~min}$ & 37.7 & 3.25 & 1.25 \\
\hline $4.0 \mathrm{~A}, 70^{\circ} \mathrm{C}, 30 \mathrm{~min}$ & 25.5 & 3.14 & 70.7 & 1.74 \\
\hline \hline
\end{tabular}

pores, while the mesopores contributed most of the surface area (Table I, Fig. 3). In contrast, the micropore volume is less than $2 \%$ of the total pore volume. It was also noticed that, while the total pore volume varied dramatically with synthesis temperature, showing, for instance, reduction by approximately $50 \%$ between 30 and $70{ }^{\circ} \mathrm{C}$, the variation in micropore volume is insignificant. The BET surface areas shown in Table I range from 25.5 to $37.7 \mathrm{~m}^{2} / \mathrm{g}$, which correspond to average crystallite sizes of $45.2-30.5 \mathrm{~nm}$. The BET particle sizes are much larger than the crystallite sizes obtained from the XRD
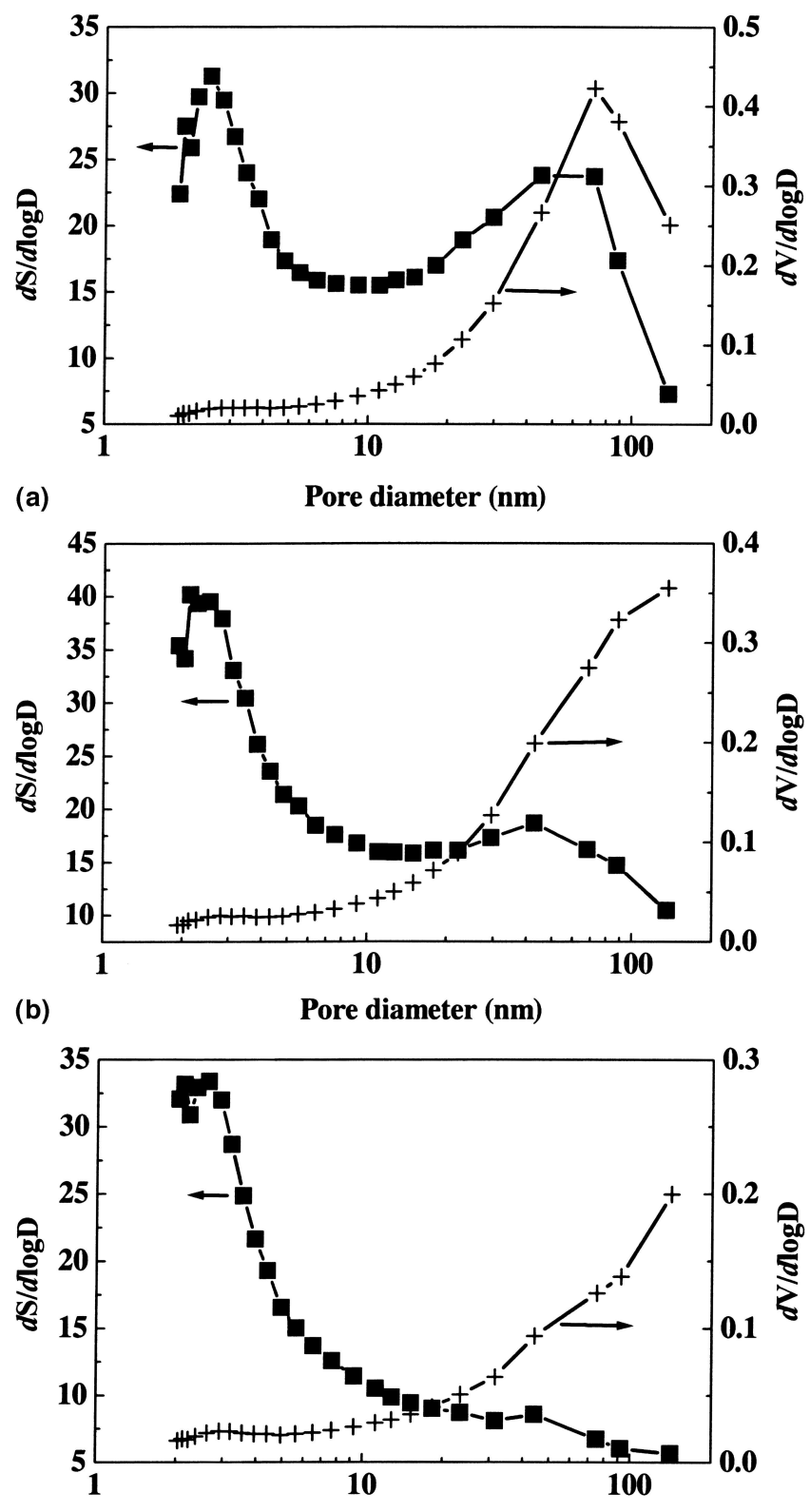

(c)

Pore diameter $(\mathbf{n m})$

FIG. 3. The surface area $(S)$ and pore volume $(V)$ distributions as a function of pore diameter $(D)$ : (a) $4.0 \mathrm{~A}, 30^{\circ} \mathrm{C}, 30 \mathrm{~min}$; (b) $8.0 \mathrm{~A}$, $30{ }^{\circ} \mathrm{C}, 30 \mathrm{~min}$; and (c) $4.0 \mathrm{~A}, 70{ }^{\circ} \mathrm{C}, 30 \mathrm{~min}$. 
studies, and this is consistent with the agglomerate nature of the crystallites.

TEM analysis showed that the black powders collected during the plateau stage have a skeletal structure of which the framework is composed of nonporous crystallites [Figs. 4(a) and 4(b)]. The crystallites exhibited distributions in size ranging from one half of to 2-3 times the XRD crystallites sizes. The pores are predominantly inter-crystallite ones with sizes ranging from a few to more than a hundred nanometers. The nonporous nature of the framework may explain the lack of micropores in the structure as revealed by the adsorption analysis (Table I). Powders collected at synthesis time beyond the plateau showed similar skeletal structures except for a thicker backbone and smaller pores. Furthermore, increasing the synthesis temperature to $70{ }^{\circ} \mathrm{C}$ was found to significantly increase the compactness within the agglomerates and hence reduce the pore volume [Fig. 4(c)]. This is also consistent with the adsorption data (Table I).

The brownish powders showed mainly spherical colloids having sizes consistent with those deduced from the XRD data, along with some needle-shaped particles
[Fig. 4(d)]. However, the population of the needles appeared to decrease with increasing synthesis time, and they were not observed in most black powders. One plausible explanation is that the needles are formed only during the early stage of the synthesis, and the total amount of these particles in the black powder is typically too small to observe under TEM.

Magnetization analysis of all the synthesized powders gave hysteresis magnetization loops, typical of the ferrimagnetic material. An example, obtained from the powder synthesis under $4.0 \mathrm{~A}$ and $30{ }^{\circ} \mathrm{C}$, is shown in Fig. 5 . Table II summarizes the magnetic properties of four different powders. The three black powders which resulted from prolonged synthesis time exhibited very similar magnetic properties, showing a saturation magnetization of approximately $75 \mathrm{emu} / \mathrm{g}$ and a coercivity $H_{\mathrm{c}}$ within the range of $118 \pm 11$ Oe. On the other hand, the brownish powder, which was obtained within shorter synthesis time, exhibited significantly lower values. These magnetic properties are comparable to those obtained by other solution chemistry routes. For instance, Khollam et al. ${ }^{13}$ reported a saturation magnetization of $70 \mathrm{emu} / \mathrm{g}$

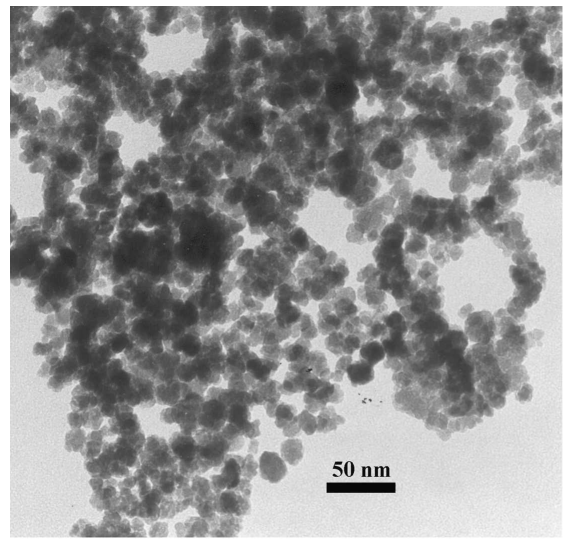

(a)

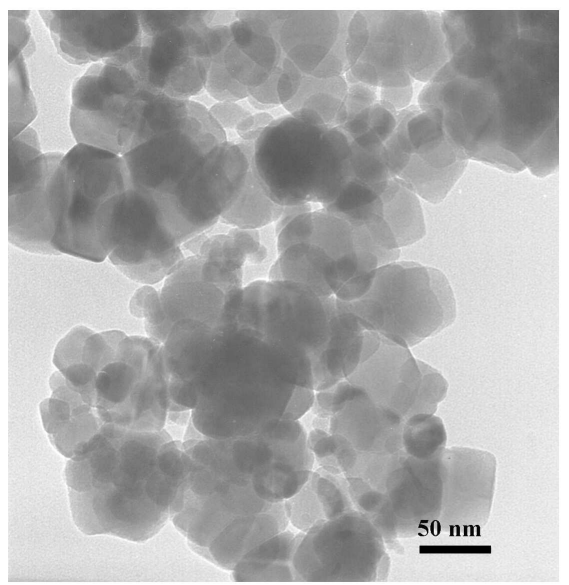

(c)

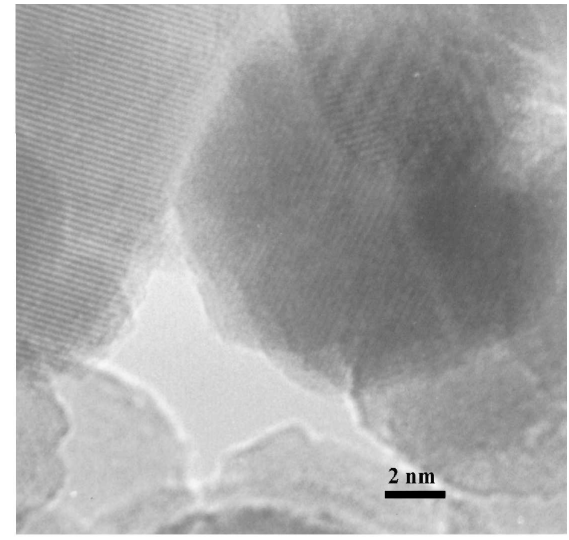

(b)

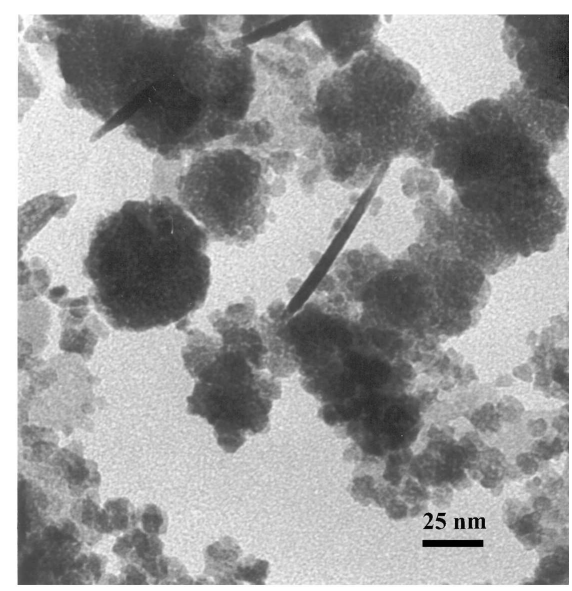

(d)

FIG. 4. TEM micrographs: (a, b) black powder synthesized at $30{ }^{\circ} \mathrm{C}(4.0 \mathrm{~A}, 30 \mathrm{~min})$; (c) the black powder at $70{ }^{\circ} \mathrm{C}$; and (d) the brownish powder at $30{ }^{\circ} \mathrm{C}$ (8.0 A, $3 \mathrm{~min}$ ). Scale bar: (a) $50 \mathrm{~nm}$, (b) $2 \mathrm{~nm}$, (c) $50 \mathrm{~nm}$, and (d) $25 \mathrm{~nm}$. 

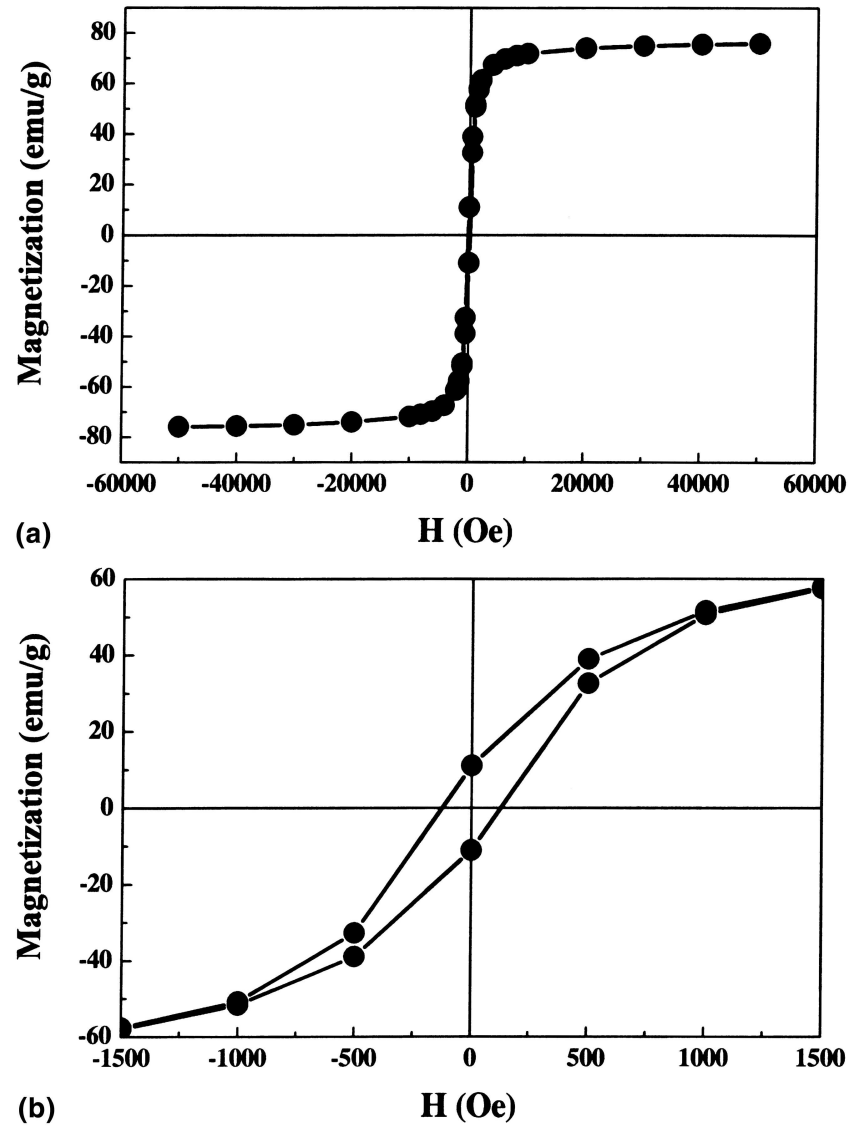

FIG. 5. Hysteresis magnetization loop of the powder synthesized under $4.0 \mathrm{~A}$ for $30 \mathrm{~min}$ at $30^{\circ} \mathrm{C}$; (a) and (b) are drawn with different $x$-axis scale to show the saturation magnetization and coercivity, respectively.

TABLE II. Magnetization properties of selected powders.

\begin{tabular}{lccc}
\hline \hline Synthesis conditions & $\begin{array}{c}\text { Saturation } \\
\text { magnetization }^{\mathrm{a}} \\
(\mathrm{emu} / \mathrm{g})\end{array}$ & $\begin{array}{c}\text { Coercivity } H_{\mathrm{c}} \\
(\mathrm{Oe})\end{array}$ & Appearance \\
\hline $4.0 \mathrm{~A}, 30^{\circ} \mathrm{C}, 30 \mathrm{~min}$ & 76 & 129 & black \\
$8.0 \mathrm{~A}, 30^{\circ} \mathrm{C}, 20 \mathrm{~min}$ & 75 & 109 & black \\
$4.0 \mathrm{~A}, 70^{\circ} \mathrm{C}, 30 \mathrm{~min}$ & 73 & 107 & black \\
$4.0 \mathrm{~A}, .30^{\circ} \mathrm{C}, 10 \mathrm{~min}$ & 60 & 8 & brownish \\
\hline \hline
\end{tabular}

${ }^{a}$ The saturation magnetization data were obtained under a field of 5 tesla and at $\sim 300 \mathrm{~K}$.

and a coercivity $H_{\mathrm{c}}$ of 178 Oe for microwavehydrothermally derived magnetite powder having XRD crystallite size of approximately $34 \mathrm{~nm}$.

In a previous study by Ying et al. ${ }^{17}$ on the reaction mechanism of the process, it has been shown that the process involves release of ferrous ions from the anode

$$
\mathrm{Fe} \leftrightarrow \mathrm{Fe}^{+2}+2 e^{-} .
$$

In the case of oxygenated solution, part of the ferrous ions can be further oxidized to $\mathrm{Fe}^{+3}$

$$
\mathrm{Fe}^{+2} \leftrightarrow \mathrm{Fe}^{+3}+e^{-}
$$

On the other hand, the cathodic reaction

$$
4 \mathrm{H}^{+}+\mathrm{O}_{2(\mathrm{~g})}+4 e^{-} \leftrightarrow 2 \mathrm{H}_{2} \mathrm{O},
$$

continues to consume $\mathrm{H}^{+}$, causing solution $\mathrm{pH}$ to increase along the course of the process. It was also suggested that the magnetite phase was formed through a serial reaction scheme consisting of first the formation of $\mathrm{Fe}(\mathrm{OH})_{3(\mathrm{~s})}$, which was subsequently reduced at cathode to form magnetite

$$
3 \mathrm{Fe}(\mathrm{OH})_{3(\mathrm{~s})}+\mathrm{H}^{+}+e^{-} \leftrightarrow \mathrm{Fe}_{3} \mathrm{O}_{4(\mathrm{~s})}+5 \mathrm{H}_{2} \mathrm{O}
$$

However, both $\mathrm{Fe}(\mathrm{OH})_{3}$ and $\mathrm{Fe}_{3} \mathrm{O}_{4}$ are insoluble in water and should precipitate right out as they are formed. It is not clear how a colloid (nucleus) can be reduced at cathode and how reaction (4) can result in crystallites with a size over $10 \mathrm{~nm}$ as observed in this study.

On the other hand, it has been shown in a precipitation $\operatorname{method}^{7}$ that nanometer-sized magnetite crystallites can be synthesized in one step from the solution containing both ferrous and ferric ions under alkaline condition. It is suggested that magnetite nuclei are formed in the electrocoagulation process via the similar reaction, namely

$$
\mathrm{Fe}^{+2}+2 \mathrm{Fe}^{+3}+8 \mathrm{OH}^{-} \leftrightarrow \mathrm{Fe}_{3} \mathrm{O}_{4(\mathrm{~s})}+4 \mathrm{H}_{2} \mathrm{O} .
$$

Coarsening of the existing nuclei may proceed by continuous incorporation of ferrous and ferric ions via surface adsorption and reaction. Coarsening by oriented attachment of nano-crystallite $e^{20,21}$ as observed for iron oxyhydroxyide by Banfield et al. ${ }^{22}$ is also possible under high concentration of nuclei. Coarsening of the existing nuclei accounts for the increase in crystallite size during the initial stage of the synthesis.

To explain the plateau in average crystallite size, we consider the competition between coarsening of the large crystallites that constitute the framework of the agglomerate and formation and coarsening of smaller free nuclei. That is, as the population of colloidal crystallites increases, crystallites start to collide and fuse together to form skeletal agglomerates. Coarsening of the connected crystallites is expected to slow down due to loss in surface area in contact with the solution, and hence formation and growth of nuclei prevail. As a result, while the total number of crystallites continuously increases with increasing synthesis time, the average size does not change significantly. This explains the existence of the plateau. On the other hand, when the amount of the skeletal agglomerates increases to certain point when the ferrous and ferric ions are rapidly consumed by the interfacial reaction, the homogeneous nucleation rate is reduced (due to low $\mathrm{Fe}^{+2}$ and $\mathrm{Fe}^{+3}$ concentrations), and coarsening of connected crystallites within the agglomerates becomes predominant. This results in the increase in average crystallite size at the later stage of the process after the plateau. 
Accordingly, the plateau is determined by the competition between nucleation and interfacial reaction, which leads to the coarsening. The plateau would occur at a smaller crystallite size in the case of a relatively higher nucleation rate and a lower interfacial reaction rate. This may explain the observation that, as shown in Fig. 2, the plateau crystallite size (PCS) is reduced as a result of an increase in the electric current. On the other hand, an increase in temperature from 30 to $70{ }^{\circ} \mathrm{C}$ led to a larger PCS. This may be interpreted as a result of a rateenhancement in the interfacial reaction greater than that in nucleation. From the thermo-kinetic point of view, this finding suggests that the interfacial reaction has a higher activation energy and hence is more temperaturesensitive than nucleation.

\section{CONCLUSION}

In summary, microstructural evolution of the magnetite powder synthesized in an electrocoagulation process was studied. Severely defective magnetite colloids were synthesized at the early stage of the process under $\mathrm{pH}$ approximately 7-8. This is followed by agglomeration among the oxide crystallites to form mesoporous skeletal agglomerates of which the framework is constituted of nonporous magnetite crystallites under $\mathrm{pH}>9$. This stage is also characterized by reduced crystal defects and a plateau in average crystallite size. At later stage, coarsening of the crystallites within the agglomerates prevails, leading to rapid increase in average crystallite size and reduction in pore opening. The meso-/macroporous nature in conjunction with a high specific surface area makes the EC magnetite powder suitable for applications that require not only large surface area but also rapid access by pore diffusion to the surface.

\section{ACKNOWLEDGMENT}

This work is supported by National Science Council under Contract No. NSC90-2214-E-002-009. Part of the TEM and magnetic studies are supported by the State of Texas through funding for the Texas Center for Superconductivity and Advanced Materials at the University of Houston.

\section{REFERENCES}

1. J. Bohacek, J. Subrt, T. Hanslik, and J. Tlaskal: Preparing particulate magnetites with pigment properties from suspensions of basic iron(III) sulfates with the structure of Jarosite. J. Mater. Sci. 28 , 2827 (1993).

2. R.L. Comstock: Modern magnetic materials in data storage. J. Mater. Sci. Mater. Electron. 13, 509 (2002).
3. K.T. Wu, P.C. Kuo, Y.D. Yao, and E.H. Tsai: Magnetic and optical properties of $\mathrm{Fe}_{3} \mathrm{O}_{4}$ nanoparticles ferrofluids prepared by coprecipitation technique. IEEE Trans. Magn. 37(4) 2651-2653 (2001).

4. M. Shinkai: Functional magnetic particles for medical application. J. Biosci. Bioeng. 94, 606 (2002).

5. J.M. Perez, F.J. Simeone, Y. Saeki, L. Josephson, and R. Weissleder: Viral-induced self-assembly of magnetic nanoparticles allows the detection of viral particles in biological media. J. Am. Chem. Soc. 125, 10192 (2003).

6. D. Beydoun, R. Amal, G.K.C. Low, and S. McEvoy: Novel photocatalyst: Titania-coated magnetite. Activity and photodissolution. J. Phys. Chem. B 104, 4387 (2000).

7. Y.S. Kang, S. Risbud, J.F. Rabolt, and P. Stroeve: Synthesis and characterization of nanometer-size $\mathrm{Fe}_{3} \mathrm{O}_{4}$ and $\gamma-\mathrm{Fe}_{2} \mathrm{O}_{3}$ particles. Chem. Mater. 8, 2209 (1996).

8. H.S. Lee, W.C. Lee, and T. Furubayashi: A comparison of coprecipitation with microemulsion methods in the preparation of magnetite. J. Appl. Phys. 85, 5231 (1999).

9. L. Diamandescu, D. Mihaila-Tarabasanu, V. Teodorescu, and N. Popescu-Pogrion: Hydrothermal synthesis and structural characterization of some substituted magnetites. Mater. Lett. 37, 340 (1998).

10. Y. Li, H. Liao, and Y. Qian: Hydrothermal synthesis of ultrafine $\alpha-\mathrm{Fe}_{2} \mathrm{O}_{3}$ and $\mathrm{Fe}_{3} \mathrm{O}_{4}$ powders. Mater. Res. Bull. 33, 841 (1998).

11. D.S. Bae, K.S. Han, S.B. Cho, and S.H. Choi: Synthesis of ultrafine $\mathrm{Fe}_{3} \mathrm{O}_{4}$ powder by glycothermal process. Mater. Lett. 37, 255 (1998).

12. S. Sun and H. Zeng: Size-controlled synthesis of magnetite nanoparticles. J. Am. Chem. Soc. 124, 8204 (2002).

13. Y.B. Khollam, S.R. Dhage, H.S. Potdar, S.B. Deshpande, P.P. Bakare, S.D. Kulkarni, and S.K. Date: Microwave hydrothermal preparation of submicron-sized spherical magnetite $\left(\mathrm{Fe}_{3} \mathrm{O}_{4}\right)$ powders. Mater. Lett. 56, 571 (2002).

14. S.R. Dhage, Y.B. Khollam, H.S. Potdar, S.B. Deshpande, P.P. Bakare, S.R. Sainkar, and S.K. Date: Effect of variation of molar ratio $(\mathrm{pH})$ on the crystallization of iron oxide phases in microwave hydrothermal synthesis. Mater. Lett. 57, 457 (2002).

15. C. Tsouris, D.W. Depaoli, and J.T. Shor: Method and apparatus to electrolytically produce high-purity magnetite particles, U.S. Patent No. 6179987 (2001).

16. C. Tsouris, D.W. DePaoli, J.T. Shor, M.Z.C. Hu, and T.Y. Ying: Electrocoagulation for magnetic seeding of colloidal particles. Colloids Surf. A 177, 223 (2001).

17. T.Y. Ying, S. Yiacoumi, and C. Tsouris: An electrocoagulation method for the formation of magnetite particles. J. Disp. Sci. Technol. 23, 569 (2002).

18. N.L. Wu, S.Y. Wang, C.Y. Han, D.S. Wu, and L.R. Shiue: Electrochemical capacitor of magnetite in aqueous electrolytes. J. Power Sources 113, 173 (2003).

19. F.W. Jones: The measurement of particle size by the x-ray method. Proc. Roy. Soc. (London) 166A, 16 (1938).

20. R. Lee Pan and J.F. Banfield: Morphology development and crystal growth in nanocrystalline aggregates under hydrothermal conditions: Insight from titania. Geochimi. Cosmochimi. Acta 63, 1549 (1999).

21. Y. Yeadon, M. Ghaly, J.C. Yang, R.S. Averback, and J.M. Gibson: Contact epitaxy observed in supported nanoparticles. Appl. Phys. Lett. 73, 3208 (1998).

22. J.F. Banfield, S.A. Welch, H. Zhang, T.T. Ebert, and R.L. Penn: Aggregation-based crystal growth and microstructure development in natural iron oxyhydroxide biomineralization products. Science 289, 751 (2000). 